\title{
Phaeochromocytoma of the urinary bladder localized by selective venous sampling and computed tomography
}

\begin{abstract}
J. L. MILLER*
M.B., Ch.B., F.C.P.(SA)

T. E. ROMAN $\ddagger$

M.B., Ch.B. F.F.Rad.(D).SA

Summary

Clinical and biochemical evidence of a catecholamine-secreting tumour was documented in a 19-yearold female presenting with malignant hypertension. The tumour was successfully localized to the pelvis by means of plasma noradrenaline assay from multiple sites, after previous attempts at localization had failed. Subsequently, computed tomographic (CT) scan allowed correct pre-operative localization to the urinary bladder.
\end{abstract}

\author{
E. J. IMMELMAN $†$ \\ M.B., Ch.B., F.C.S.(SA), F.R.C.S. (Eng) \\ B. MERVIS $\ddagger$ \\ M.B., B.Ch., D.M.R.D.F.F.Rad.(D), SA
}

Departments of *Medicine, †Surgery and $\ddagger$ Radiology, Groote Schuur Hospital and University of Cape Town, South Africa

KEY WORDS: phaeochromocytoma, bladder, venous sampling, CT scan.

\section{Introduction}

The majority of phaeochromocytomas arise from the adrenal medulla and, including those in ectopic locations, more than 95\% are intra-abdominal. Extraadrenal phaeochromocytomas are difficult to localize pre-operatively (Engelman, 1977). A patient with an extra-adrenal phaechromocytoma is reported, where successful localization to the bladder was achieved by computed tomographic (CT) scan subsequent to the results of plasma noradrenaline assay in samples taken from multiple sites (Moss, Greenbaum and Sever, 1980; Huw Jones et al., 1979). Previous attempts at localization had failed.

\section{Case report}

A 19-year-old female presented with bitemporal headaches, and was found to have a blood pressure of $290 / 180 \mathrm{mmHg}$ and bilateral papilloedema on fundoscopy. Because of restlessness and agitation, postu-

Reprint requests: J. L. Miller, Division of Endocrinology, Department of Medicine, University of Cape Town Medical School, Observatory, 7925, South Africa. ral hypotension could not be assessed. After normotension had been achieved with oral prazosin, she admitted to paroxysms of headache, palpitations and diaphoresis occurring at infrequent intervals, with no obvious precipitating factors. Urinalysis was entirely normal. Of significance was the fact that 4 years previously, she presented with 'pre-eclamptic toxaemia'. After control of her hypertension, she delivered a healthy infant vaginally but was lost to follow-up.

Blood pressure was controlled on $\alpha$-blockade, with postural hypotension being a troublesome feature. $\beta$ blockade was introduced because of persistent sinus tachycardia. A clinical diagnosis of a phaeochromocytoma was confirmed biochemically, with urinary vanillyl-mandelic acid, total metanephrines and total catecholamines being persistently and markedly elevated.

Attempts at pre-operative localization of the tumour by means of abdominal computed tomography (CT) and selective arteriography failed to reveal any tumour. The cystographic phase of the arteriogram was unsuccessful in documenting any tumour. Selective venographic sampling with assay of plasma noradrenaline (Cat-A-Kit, Upjohn Diagnostics, Michigan, U.S.A.) from various sites was performed. Plasma noradrenaline concentrations in peripheral plasma was grossly elevated at $20 \mathrm{ng} / \mathrm{ml}$ (upper limit of normal $0.8 \mathrm{ng} / \mathrm{ml}$ ). Highest plasma noradrenaline concentration was found in blood from the left common iliac vein, suggesting origin from left side of the pelvis (Fig. 1). Repeat CT scan of the pelvis revealed a $6.3 \times 4.3 \mathrm{~cm}$ mass arising from the right dome of the bladder (Fig. 2) which was subsequently confirmed on ultrasonography.

Under general anaesthesia, cystoscopy was performed, but no mass lesion or ulceration of the bladder mucosa was observed. However, a prominence of sub-mucosal vessels was observed overlying 


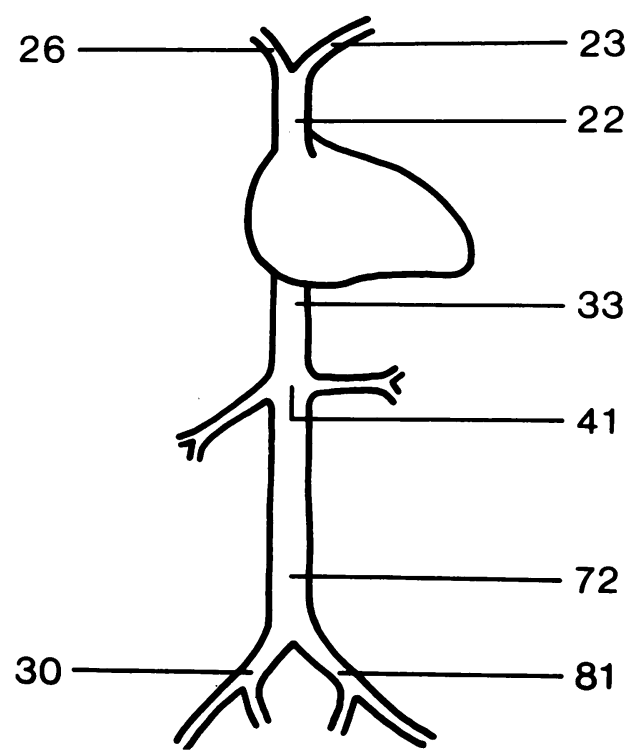

FIG. 1. Plasma noradrenaline $(\mathrm{ng} / \mathrm{ml})$ in multiple-site venous samples.

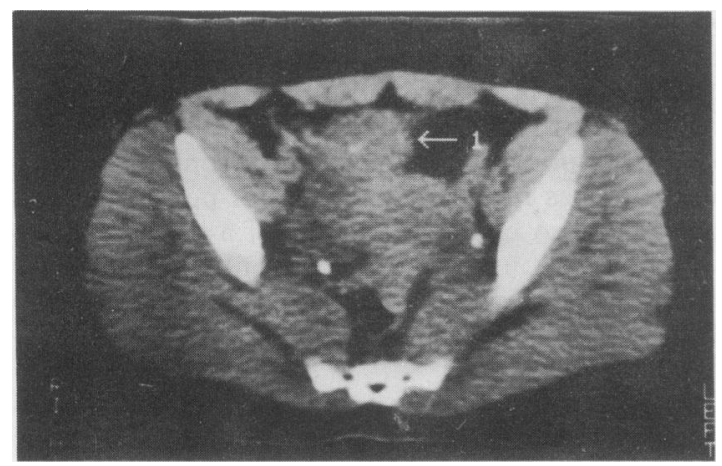

FIG. 2. CT scan of pelvis, showing the mass (arrowed) on the right side of the bladder.

the lesion. Laparotomy was then performed, at which a $5 \mathrm{~cm}$ benign phaeochromocytoma was confirmed arising from the dome of the bladder, slightly to the right of the midline, and was removed by partial cystectomy. Postoperatively, the patient's blood pressure and vanillyl-mandelic acid excretion returned to normal.

\section{Discussion}

Phaeochromocytomas of the bladder are rare tumours, accounting for less than $0.06 \%$ of all bladder neoplasms (Laestma and Price, 1971) and, to date, only about 80 cases have been published (Meyer, Sane and Drake, 1979; Ochi et al., 1981).
Vesical phaeochromocytomas usually present with symptoms of catecholamine-excess related to micture ition (Flanigan et al., 1980). Hypertension was noted in $60 \%$ of cases with bladder phaeochromocytoma, haematuria in 59\% and micturitional attacks in $4 \%$ (Ochi et al., 1981). The case reported lacked anty symptoms of catecholamine excess related to mictuntion, haematuria was not documented and of note $\frac{15}{5}$ that, 4 years before this current problem, 'pregnanc:related hypertension' did not in any way precipitatea hypertensive crisis during vaginal delivery of csa healthy infant.

Anatomically, bladder phaeochromocytomas aife most commonly located in the trigone $(25 \%)$ or dome (24\%) and are visible at cystoscopy in $84 \%$ of reporteg cases (Ochi et al., 1981). The case reported lacked the usual cystoscopic findings of bladder mass or ulcerâ. tion of the bladder mucosa.

Localization of the phaeochromocytoma was ingtially attempted by computed tomography, as this technique is non-invasive and has been reported ox being successful in $91 \%$ of cases studied (Stewart $\mathscr{E}^{\mathrm{E}}$ al., 1978). The adrenals were normal in size and shape and no intra-abdominal masses were present. At the time, limited cuts of the pelvis at $30 \mathrm{~m}$ 要 intervals were obtained without vesical contrast, afd were reported as normal. Selective venographic sampling for plasma noradrenaline localizedo toe tumour to the left pelvis. Repeat CT scan of the pelvis was then successful in localizing the mas to the right dome of the bladder. This emphasizes the importance of meticulous attention to detail whe performing these procedures, in order not to miss mass lesions in relatively unusual localities.

The reason for the localization of the tumour to the left side of the pelvis by venographic sampling, despite right-sided location, was evident at surgery. The vascular supply was from a prominent leash vessels coursing across the dome of the bladder towards the left internal iliac system.

Although the literature has mention of bladder phaeochromocytomas being localized by selecti文e venographic sampling for noradrenaline, in none \&f these reports was this the initial investigation, the tumour initially being suspected to be in the bladder because the patients volunteered symptoms related micturition. The tumours were initially localized the bladder by either intravenous urography angiography, and subsequently selective venoprs sampling was done as confirmatory evidence (Khan et al., 1982; Timmis, Brown and Allison, 1981).

To the best of our knowledge, this is the fifgt documented case of a bladder phaeochromocytoma being initially localized by selective venograp花c sampling, and subsequently by CT scan and ultesound (Modlin et al., 1979; Ochi et al., 1981; Flanigazn et al., 1980; Das and Lowe, 1980; Scott and Eversote, 
1960) before surgical intervention, and emphasizes the value of selective venographic sampling for localization of phaeochromocytomas when non-invasive techniques fail.

\section{Acknowledgments}

We would like to thank Dr H. Brown for referring the patient, Dr E. P. Harries-Jones for performing the venous sampling and the Department of Chemical Pathology, Tygerberg Hospital, for the plasma noradrenaline assays.

\section{References}

DAS, S. \& LowE, P. (1980) Malignant pheochromocytoma of the bladder. Journal of Urology, 123, 282.

Engelman, K. (1977) Phaeochromocytoma. In: Clinics in Endocrinology \& Metabolism Vol. 6 Number 3, p. 769. W.B. Saunders, Philadelphia.

Flanigan, R.C., Wittman, R.P., Huhn, R.G. \& Davis, C.J. (1980) Malignant pheochromocytoma of the urinary bladder. Urology, 16, 386.

Huw Jones, D., Allison, D.J., Hamilton, C.A. \& Reid, J.L. (1979) Selective venous sampling in the diagnosis and localization of phaeochromocytoma. Clinical Endocrinology, 10, 179.
Khan, O., Chisholm, G.D., Williams, G. \& Welbourn, R.B. (1982) Phaeochromocytomas of the bladder. Journal of the Royal Society of Medicine, 75, 17.

LAESTMA, J.E. \& PRICE, E.B. (1971) Paraganglioma of the urinary bladder. Cancer, 28, 1063.

MEYER, J.J., SANE, S.M. \& DRAKE, R.M. (1979) Malignant paraganglioma of the urinary bladder: report of a case and review of the literature. Pediatrics, 63, 879.

Modlin, I.M., Farndon, J.R., ShePherd, A., Johnston, I.D.A., KENNEDY, T.L., MONTGOMERY, D.A.D. \& WelbouRN, R.B. (1979) Phaeochromocytomas in 72 patients: clinical and diagnostic features, treatment and long term results. British Journal of Surgery, 66, 456.

Moss, S., Greenbaum, R. \& Sever, P.S. (1980) Preoperative localization of a phaeochromocytoma using plasma noradrenaline concentrations in multiple-site samples. Journal of the Royal Society of Medicine, 73, 139.

OCHI, K., Yoshioka, S., Morita, M. \& TAKLUChI, M. (1981) Pheochromocytoma of bladder. Urology, 27, 228.

ScotT, W.W., Eversole, S.L. (1960) Pheochromocytoma of the urinary bladder. Journal of Urology, 83, 656.

Stewart, B.H., Bravo, E.L., HaAga, J., Meaney, T.F. \& Tarazi, R. (1978) Localization of pheochromocytoma by computed tomography. New England Journal of Medicine, 299, 460.

Timmis, J.B., BRown, M.J. \& Allison, D.J. (1981) Therapeutic embolization of phaeochromocytoma. British Journal of Radio$\log y, 54,420$.

(Accepted 16 December 1982) 